\title{
A Comparative Study Of Smartphone Addiction Drivers' Effect On Work Performance In The U.S. And Korea
}

Won-jun Lee, Cheongju University, Korea

Seungjae Shin, Mississippi State University, USA

\begin{abstract}
Smartphone addiction is a new phenomenon when a smartphone becomes a necessity in our daily life. This study explores smartphone addiction drivers and their results. Four factors such as ease of use, emotional lift, preference of social interaction, and flow, are used for drivers and neglect of work is used as a proxy of addiction result. In the result of structured equation modeling analysis, preference of social interaction is not related with smartphone usage behaviors such as usage frequency and usage hours. In the analysis of U.S. users, emotional lift is a driver and in the analysis of Korean users, ease of use and flow are drivers for smartphone addiction. There is a significant relationship between smartphone use and neglect of work in both countries. Even if there is a trend of converging user behavior because of globalization, drivers for smartphone addiction are different in the U.S. and Korea.
\end{abstract}

Keywords: Smartphone Addiction; Structured Equation Model; Work Performance

\section{INTRODUCTION}

\& martphone is not just a calling device, but it is a multi-purpose device such as social networking, e-mailing, web browsing, texting, taking pictures, media playing, organizing schedules, and GPS navigating. In addition, with an introduction of near field communication technology, smartphones become a mobile wallet. In the 1990s, internet was commercialized and the number of internet users has increased exponentially with an advent of graphical web browsers. In 1998, internet addiction was coined by Dr. Kimberly Young, who developed the Internet Addiction Diagnostic Questionnaire. After the introduction of Apple's iPhone in 2007, mobile phones have been gradually replaced by smartphones. Smartphones change people's daily life and smartphone become a necessity of life. As the smartphone penetration rate increases, the dependency of smartphone increases (Shin, 2014) and negative effects by compulsive use of smartphones come in (Lee, Chang, Lin, and Cheng, 2014).

According to a report about the U.S. smartphone market by comScore, a leading digital media analytic company, 182 million people in the U.S. owned a smartphone, which is $74.9 \%$ market penetration in 2014. According to a report of the Cellular Telephone Industry Association, wireless penetration is $110 \%$ in 2014 and the U.S. is a world leader of 4G mobile service. Korea has been a pioneer for broadband mobile service in the early 2000s (Yoo, Lyytinen, \& Yang, 2005) and Korea is the first country to widely introduce mobile TV services to its mobile phone users (Shim, Shin, and Weiss, 2006). According to the statistics by the Korea Communications Commission (KCC), in 2014, the wireless penetration was over $114 \%$ and $70 \%$ of Korean wireless subscribers were smartphone users.

Several international projects about smartphone user behaviors include samples from Korea and the U.S. Google conducted a project, "Our Mobile Planet", which surveyed 48 countries to understand smartphone adoption and users' behaviors. In 2013, smartphone penetration rates of Korea and the U.S. are $73 \%$ and $56 \%$ respectively. According to the 2012 Time Mobility Poll, which surveyed smartphone user behaviors of eight countries, including the U.S. and Korea, Koreans were more dependent on smartphones than smartphone users of the other seven countries. As a byproduct, Korea has historically suffered from internet addiction (Block, 2008) and recently it has suffered from smartphone addiction (Lee, 2013). As the Korean Government considers internet addiction as one of the public health 
issues (Block 2008), current studies about smartphone addiction on Korean high school and college students show the potential risk for smartphone addiction (Lee, 2013; Seo et al., 2013; Park \& Lee, 2014; Mok et al., 2014). It is a phenomenon in Korea but it could also be a phenomenon of any country with a high penetration of smartphones.

Due to the relative early stage of smartphone service, there are only a few empirical studies on smartphone service addiction. The comparative study of intent is to develop an initial relationship model between smartphone addiction itself and its drivers and compare the results of two countries, U.S. and Korea. This paper is organized in the following order: In the next section, the authors explore literature review of smartphone addiction. In the third section, the authors explain the research plan which includes hypothesis and questionnaire development. In the fourth section, analysis and results are presented. The discussion and conclusion sections are added at the end.

\section{LITERATURE REVIEW}

Internet Use Disorder (IUD), is a preoccupation with internet activity and online gaming. For the IUD, excessive use with a loss of sense of time is known as a big factor for internet addiction (Block, 2008). Block (2008) also pointed out that South Korea had a serious internet addiction problem compared to the U.S. As more and more people use smartphones for their online activity, it is a general trend that the internet addiction focuses on smartphone addiction.

Lee et al. (2014) analyzed college students' smartphone usage patterns related to smartphone overuse. They divided the subjects into two groups: risk group and non-risk group. They found that the risk group spent longer time in smartphone usage and the Mobile Instant Message (MIM) app is the most frequently used app. The risk group spent more time on MIM which was triggered by MIM notification. Park and Lee (2011) investigated that three factors for compulsive smartphone usage are satisfaction, loneliness, and personal innovativeness. Seo et al. (2013) studied the relationship between smartphone addiction and PC internet addiction. They found there is a positive relationship between the smartphone addiction rate scales and Young's internet addiction scales. Park and Lee (2013) investigated the difference of smartphone usage patterns between two smartphone addiction tendency groups, high and low, which is grouped by self-evaluation. They found that more females belonged to the high addiction tendency group and the high addiction tendency group has a higher shyness, loneliness, and depression score and a lower self-esteem score.

Bernroider, Krumay and Margiol (2014) studied the negative effect of smartphone addiction with technology acceptance. They integrated the technology acceptance model in their proposed smartphone addiction model. They found that perceived security, perceived usefulness, and perceived enjoyment are positively related with smartphone usage behavior and these relations are positively inflated by smartphone addiction. Among the above three factors, perceived enjoyment is the most important factor to influence the smartphone addiction.

There are several studies about comparative analysis of mobile services and user behaviors between the U.S. and Korea. While the U.S. is one of the largest mobile service market, Korea is one of the top countries in OECD member countries in the wireless broadband subscription rate (Shin, Lee, and Odom, 2014). Cho (2009) found that when purchasing a mobile service, convenience is more sensitive to mobile users in Korea than those in the U.S. Kang and Jung (2014) compared basic needs for smartphone use in Korea and U.S. They found that in contrast to U.S. smartphone users, those in Korea believed that self-esteem did not positively affect smartphone use because $70 \%$ of mobile users have smartphones and they consider the smartphone as a necessity. L. Shin (2014) studied comparison of smartphone usage pattern between the U.S. and Korea. He found Korean users had a higher usage dependency level than U.S. users.

\section{HYPOTHESIS DEVELOPMENT}

Measures of the variables were developed in several stages. All the measures were borrowed from the previous studies and modified to be suitable for the smartphone addiction research context. The hypotheses in this research are the four factors such as ease of use, preference for online social interaction (POSI), flow, and emotional lift would influence smartphone use, which also influences the neglect of work as a result of compulsive usage.

Chen (2007) insisted that individual belief of ease of use could predict the extent to which users will use a mobile service. Cho (2008) revealed that ease of use is one of factors to influence satisfaction of mobile users. Shin and Lee 
(2014) also argued that ease of use was a construct to predict intention to use a smartphone payment. The authors assume that ease of use will affect smartphone usage pattern.

H1: Ease of Use has a positive effect on smartphone use.

Faber and O'Guinn (1992) stated that emotional lift was one of the main factors to influence behavior of compulsive buying. LaRose (2001) said that there were many surveyed evidences of compulsive buying on the internet, which could lead to behavioral addiction. Moore (2009) ascertained that emotional lift was a critical factor of compulsive buying disorder. According to the survey about mobile payment (Shin, et al., 2014), 56\% of U.S. smartphone users had an experience of mobile shopping and $48 \%$ of smartphone users in Korea had an experience of mobile banking. The authors assume that emotional lift is also a factor for use of smartphone because mobile shopping and mobile banking are parts of buying activities through smartphones.

H2: Emotional lift has a positive effect on smartphone use.

Caplan (2010) stated that POSI has a positive predictor of compulsive use of internet through deficient self-regulation. Casey and Leung (2015) found that psychological attributes such as loneliness and shyness had negative relationship with face-to-face communications, which lead to smartphone addiction significantly. Kwon et al. (2013) argued that smartphone users with cyberspace-oriented relationship, "a feeling of relationship obtained through a smartphone", had more intimate feelings with online friends than with real life friends and they are susceptible to compulsive use of smartphones. The authors assume that POSI is a factor for use of smartphone.

H3: Preference of online social interaction has a positive effect on smartphone use.

Huizingh and Hoekstra (2003) argued that the flow which online buyers experienced during visiting online store sites, was the most important factor for describing the attitudinal changes of online buyers from viewing a product advertisement to product purchase. Chou and Ting (2003) found that flow experience showed much stronger impact on cyber gaming addiction than any other factor. Voiskounsky, Mitina, and Avetisova (2004) ascertain that flow experience was the most important factor in the online gaming addiction. Kamssu and Siekpe (2012) examined the relationship between online flow experience and internet addiction. They found that internet flow seemed to extend the duration of internet usage which lead to internet addiction. Hsu, Chang, and Chen (2012) investigated the relationship between flow experience and internet shopping behavior. They found that flow experience was positively related to internet shopping behaviors such as continuance intention, purchase intention and impulsive buying. The authors assume that flow is a factor for use of smartphone.

H4: Flow has a positive effect on smartphone use.

A level of smartphone use in this study is determined by usage frequency and usage length. Derks and Bakker (2012) investigated smartphone users' behavior for work-home interference, which is defined as "a process of negative interaction between work and home domains." They found that intensive smartphone users had a positive relationship with work-home interference, which were also a positive relationship with state levels of burn out. The findings in their study show that a level of smartphone usage influences work performance. Lee (2013) found that among various factors for smartphone addiction, neglect of work, escape reality, and lack of control are strong effective factors. Kim et al. (2013) found disturbance of adaptive functions and virtual life orientation are important factors for smartphone addiction, which are similar as neglect of work and escape reality. Kibona and Mgaya (2015) investigated impact of smartphone addiction on academic performance of college students. They revealed that smartphone addiction has a negative relationship with academic performance. The authors assume there is a strong relationship of neglect of work from smartphone usage hours and usage frequency.

H5: Smartphone use has a positive effect on neglect of work.

Figure 1 represents the research model and its hypotheses used in this study. Table 1 provides a list of all measurement items. 
Table 1. List of Measurements

\begin{tabular}{|c|c|}
\hline Variable & Measure \\
\hline Ease of use & $\begin{array}{l}\text { (a1) My interaction with smartphone would be clear and understandable. } \\
\text { (a2) Integrating with smartphone would not require a lot of mental effort } \\
\text { (a3) I find smartphone would be easy to use } \\
\text { (a4) I find it easy to get smartphone to do what I want it to do }\end{array}$ \\
\hline Emotional lift & $\begin{array}{l}\text { (a5) I use smartphone because using it makes me happy } \\
\text { (a6) Using smartphone is fun. } \\
\text { (a7) I get a real 'high' from using smartphone }\end{array}$ \\
\hline $\begin{array}{l}\text { Preference for } \\
\text { online social } \\
\text { interaction }\end{array}$ & $\begin{array}{l}\text { (a8) I am treated better in my mobile social relationships (ex: Facebook) than in my face-to-face relationships. } \\
\text { (a9) I am more confident socializing in mobile social service rather than face-to-face. } \\
\text { (a10) I feel safer relating to people in mobile social service rather than face-to-face. }\end{array}$ \\
\hline Flow & $\begin{array}{l}\text { (a11) I feel like I am totally absorbed by smartphone. } \\
\text { (a12) While using the smartphone, time seemed to go by very quickly. } \\
\text { (a13) While using the smartphone, I forget about my immediate surroundings. } \\
\text { (a14) While using the smartphone, I am not aware of how long I have been there. }\end{array}$ \\
\hline $\begin{array}{l}\text { Neglect of } \\
\text { Work }\end{array}$ & $\begin{array}{l}\text { (a15) My work suffers because of the amount of time I spend mobile. } \\
\text { (a16) My job performance suffers from smartphone. } \\
\text { (a17) I use smartphone longer than intended during I work. } \\
\text { (a18) I lose sleep due to late night use of smartphone and reach my office late. }\end{array}$ \\
\hline $\begin{array}{l}\text { Smartphone } \\
\text { Use }\end{array}$ & $\begin{array}{l}\text { (a19) Daily frequency for using a smartphone } \\
\text { (a20) Daily hours for using a smartphone }\end{array}$ \\
\hline
\end{tabular}

Figure 1. Research Model

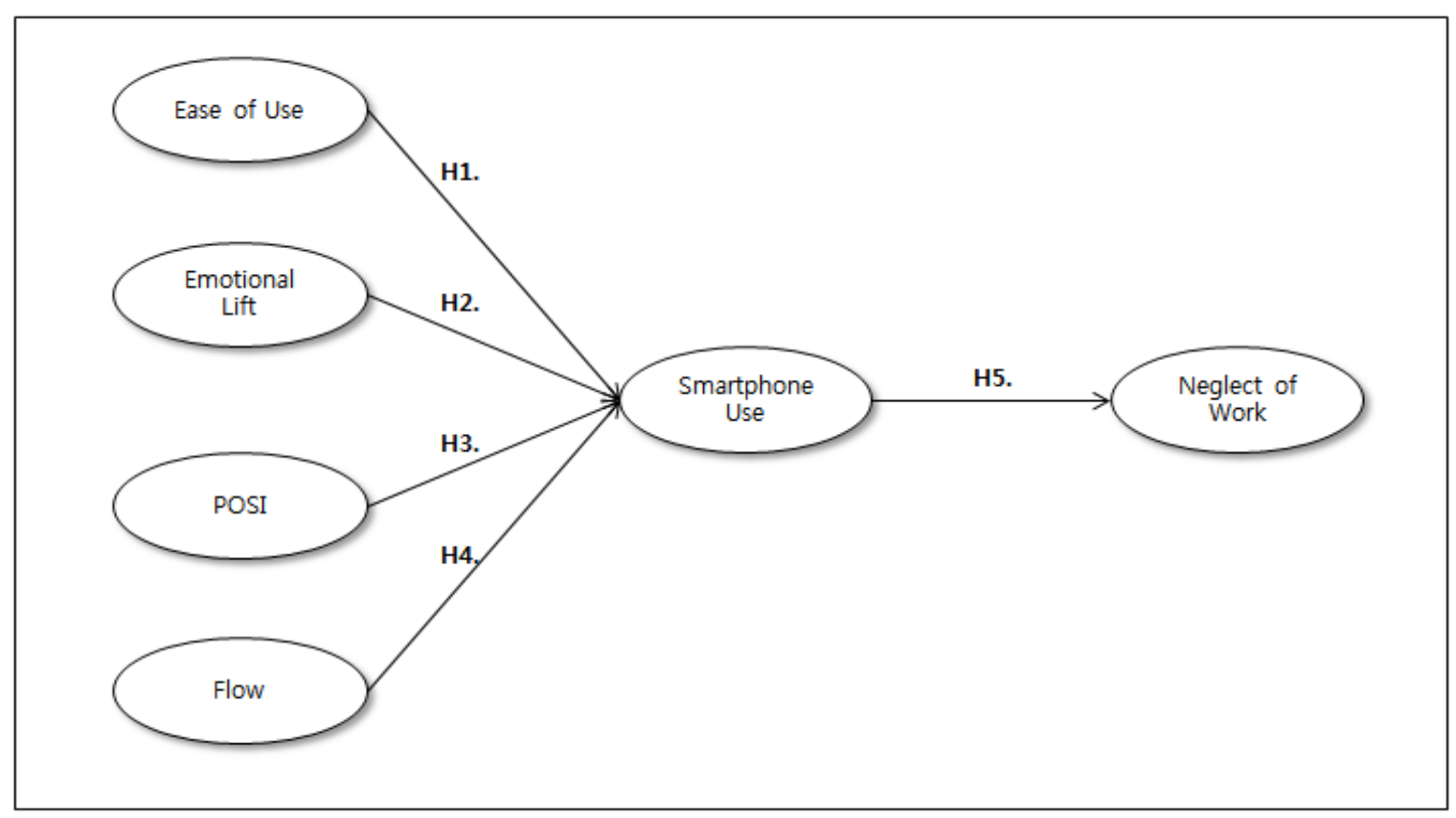

\section{ANALYSIS AND RESULT}

\subsection{Data Collection Method}

In order to collect data, structured questionnaires are designed to contain multiple questions. The questionnaires are submitted to college students in the U.S and Korea by using an internet survey site. The questionnaires are written in both Korean and English and both versions are identical. 570 responses were received between October and November, 2014. In the process, respondents who are not using smartphone service are excluded. As a result, 543 
questionnaires out of 570 are selected for the analysis. The descriptive analysis of the data shows that $46.8 \%$ is U.S. college students and $53.2 \%$ is Korean and their average age is 24 years old. This statistic indicates that most of the respondents tend to be young college students in their twenties. Table 2 presents demographic information of the samples.

Table 2. Demographic Information

\begin{tabular}{c|c|c|c}
\hline Country & Gender & Age & Occupation \\
\hline U.S (46.8\%) & Male (37.0\%) & $18 \sim 25$ years $(81.2 \%)$ & \multirow{2}{*}{ Student $(100.0 \%)$} \\
\hline Korea (53.2\%) & Female (63.0\%) & 26 or higher $(18.8 \%)$ & \\
\hline
\end{tabular}

\subsection{Reliability and Validity}

Reliability and validity of measures in the questionnaire were tested by analyzing Cronbach's alpha score and performing factor analysis. Internal consistency was initially evaluated by computing Cronbach's alpha score (Table 3). Cronbach's alpha was found to be more than 0.70 , suggested by Nunnally (1967), in most of the variables except emotional lift, whose Cronbach's alpha value was 0.692 .

Table 3. Cronbach's Alpha

\begin{tabular}{l|c|c|c}
\hline \multicolumn{1}{c|}{ Variable } & Mean (SD) & Alpha score & Number of item \\
\hline Ease of use & $3.928(.612)$ & .767 & 4 \\
\hline Preference for online social interaction & $2.232(.885)$ & .786 & 3 \\
\hline Flow & $3.023(.746)$ & .717 & 4 \\
\hline Emotional lift & $3.276(.733)$ & .692 & 3 \\
\hline Smartphone use & $3.575(.900)$ & .830 & 2 \\
\hline Neglect of Work & $2.450(.954)$ & .839 & 4 \\
\hline
\end{tabular}

\subsection{Factor Analysis}

To test the validity of variables, exploratory factor analysis is executed, selecting principal component analysis method and VARIMAX rotation option. In the test, four factors are extracted successfully (Table 4).

Table 4. Exploratory Factor Analysis

\begin{tabular}{|c|c|c|c|c|c|}
\hline Variable & Item & $\mathbf{E U}$ & EL & POSI & Flow \\
\hline \multirow{4}{*}{ Ease of use (EU) } & a3 & 0.795 & 0.132 & -0.073 & -0.027 \\
\hline & $\mathrm{a} 4$ & 0.785 & 0.115 & 0.037 & -0.064 \\
\hline & a1 & 0.747 & 0.050 & -0.020 & 0.055 \\
\hline & $\mathrm{a} 2$ & 0.721 & -0.057 & -0.019 & 0.102 \\
\hline \multirow{3}{*}{ Emotional lift (EL) } & a5 & 0.001 & 0.855 & 0.034 & 0.113 \\
\hline & a7 & -0.051 & 0.799 & 0.053 & 0.187 \\
\hline & a6 & 0.291 & 0.586 & -0.005 & 0.013 \\
\hline \multirow{3}{*}{$\begin{array}{l}\text { Preference for online } \\
\text { social interaction (POSI) }\end{array}$} & a10 & -0.003 & 0.062 & 0.868 & 0.089 \\
\hline & a9 & -0.012 & 0.104 & 0.851 & 0.097 \\
\hline & a8 & -0.048 & -0.052 & 0.773 & 0.053 \\
\hline \multirow{4}{*}{ Flow } & a14 & -0.006 & 0.120 & 0.089 & 0.847 \\
\hline & a13 & -0.015 & 0.013 & 0.097 & 0.824 \\
\hline & a11 & 0.015 & 0.470 & 0.123 & 0.553 \\
\hline & a12 & 0.174 & 0.401 & 0.000 & 0.472 \\
\hline \multicolumn{2}{|l|}{ Eigenvalue } & 3.233 & 2.495 & 1.797 & 1.216 \\
\hline \multicolumn{2}{|l|}{$\%$ of variance } & $23.08 \%$ & $17.82 \%$ & $12.83 \%$ & $8.68 \%$ \\
\hline \multicolumn{2}{|l|}{ Total variance } & & & & $62.43 \%$ \\
\hline
\end{tabular}

In addition, confirmatory factor analysis (Table 5) was performed using AMOS 20 to check convergent validity and discriminant validity. The overall model fits including GFI, AGFI, NFI, CFI, AVE and composite reliability were satisfactory in general. The analysis outcome proved that the proposed model and the sample data were good for the further analysis and unidimensionality of all constructs were satisfactory. 
Table 5. Confirmatory Factor Analysis

\begin{tabular}{|c|c|c|c|c|}
\hline Construct & Variable & Std. Estimate(p-value) & AVE & Composite Reliability \\
\hline Ease of use & $\begin{array}{l}\text { a1 } \\
\text { a2 } \\
\text { a3 } \\
\text { a4 } \\
\end{array}$ & $\begin{array}{l}.614(.000) \\
.601(.000) \\
.765(.000) \\
.722(.000) \\
\end{array}$ & .461 & .772 \\
\hline Emotional Lift & $\begin{array}{l}\mathrm{a} 5 \\
\mathrm{a} 6 \\
\mathrm{a} 7 \\
\end{array}$ & $\begin{array}{l}.840(.000) \\
.471(.000) \\
.701(.000)\end{array}$ & .472 & .719 \\
\hline POSI & $\begin{array}{c}\text { a8 } \\
\text { a9 } \\
\text { a10 }\end{array}$ & $\begin{array}{l}.588(.000) \\
.811(.000) \\
.837(.000)\end{array}$ & .568 & .794 \\
\hline Flow & $\begin{array}{l}\text { a11 } \\
\text { a12 } \\
\text { a13 } \\
\text { a14 }\end{array}$ & $\begin{array}{l}.629(.000) \\
.503(.000) \\
.641(.000) \\
.735(.000)\end{array}$ & .400 & .723 \\
\hline
\end{tabular}

\subsection{SEM Analysis}

The hypothesized relations are tested using SEM (structural equation modeling) technique. The variables are evaluated by a five point Likert scale ( $1=$ very little, $3=$ medium, $5=$ very much). In the test, most hypotheses are supported except H3. The results of causal relations between smartphone addiction driving variables and smartphone use indicate that $\mathrm{H} 1, \mathrm{H} 2$, and $\mathrm{H} 4$ are supported. Ease of use has a positive relationship with smartphone use. Emotional lift and flow has a positive relationship with smartphone use. However, in this model, we do not witness significant impacts of reference for POSI. The relationship between smartphone use and neglect of work showed a very strong relationship. Figure 2 and Table 6 present the outcomes of SEM analysis.

Table 6. SEM Analysis Result

\begin{tabular}{l|c|c|c|c}
\hline \multicolumn{1}{c|}{ Hypothesis } & $\boldsymbol{\beta ( S t d . ~} \boldsymbol{\beta})$ & SE & CR & P \\
\hline H1. Ease of use $\rightarrow$ Smartphone Use & $.153(.098)$ & .076 & 1.999 & $.046^{* *}$ \\
\hline H2. Emotional lift $\rightarrow$ Smartphone Use & $.178(.188)$ & .063 & 2.831 & $.005^{*}$ \\
\hline H3. POSI $\rightarrow$ Smartphone Use & $-.020(-.015)$ & .066 & -.307 & .759 \\
\hline H4. Flow $\rightarrow$ Smartphone Use & $.443(.402)$ & .081 & 5.448 & $.000^{*}$ \\
\hline H5. Smartphone Use $\rightarrow$ Neglect of Work & $.605(.457)$ & .066 & 9.182 & $.000^{*}$ \\
\hline
\end{tabular}

Fit: $\mathrm{x}^{2}$ (d.f) $=697.009(159), \mathrm{p}=.000, \mathrm{GFI}=.885, \mathrm{AGFI}=.848, \mathrm{NFI}=.834, \mathrm{CFI}=.866, \mathrm{RMSEA}=.079$ ${ }^{*} \mathrm{p}<0.01,{ }^{* *} \mathrm{p}<0.05$ 
Figure 2. SEM Analysis of Combined Data

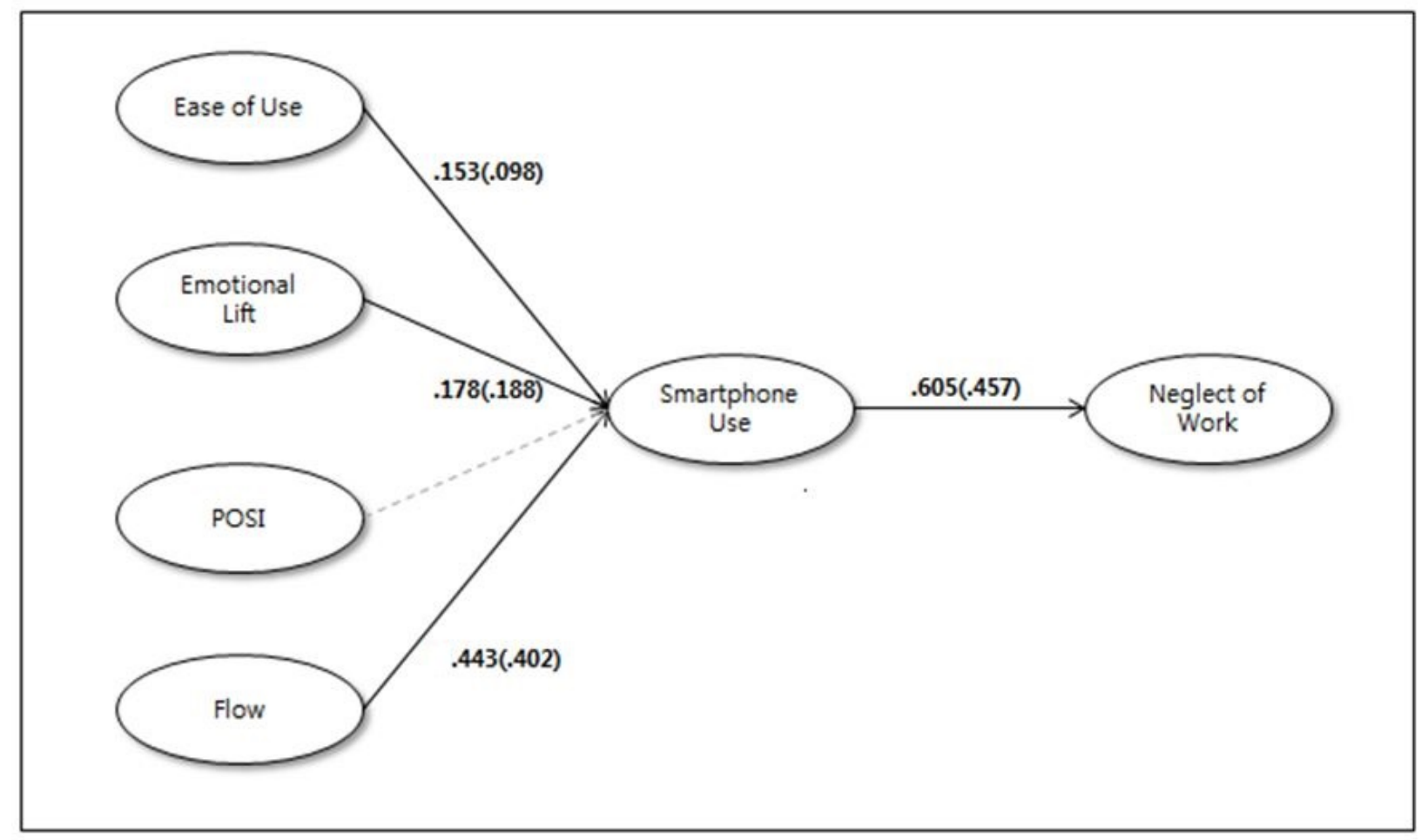

\subsection{Comparison of Analysis for U.S. and Korea}

To test the difference between the two countries, SEM analyses were performed again after separating the data into two groups according to the respondents' country (Figure 3 and Table 7). In the output of the U.S. analysis H2 and H5 are supported. Emotional lift has a positive relation with smartphone use. In the output of Korea analysis, H1, H4, and $\mathrm{H} 5$ are supported. Ease of use and flow have a positive relation with smartphone use. In both countries, smartphone use has a positive relation with neglect of work. The difference between the analyses of the two countries is drivers for smartphone use.

Table 7. Analysis Result for U.S. and Korea

\begin{tabular}{c|l|c|c|c|c}
\hline Country & \multicolumn{1}{c|}{ Hypothesis } & $\boldsymbol{\beta ( S t d . ~} \beta$ & S.E & C.R & P \\
\hline \multirow{5}{*}{ U.S } & H1. Ease of use $\rightarrow$ Smartphone use & $.050(.025)$ & .146 & .341 & .733 \\
\cline { 2 - 6 } & H2. Emotional lift $\rightarrow$ Smartphone use & $.465(.428)$ & .453 & 3.039 & $.002^{*}$ \\
\cline { 2 - 6 } & H3. POSI $\rightarrow$ Smartphone use & $-.116(-.067)$ & .178 & -.652 & .515 \\
\cline { 2 - 7 } & H4. Flow $\rightarrow$ Smartphone use & $.215(.202)$ & .130 & 1.659 & .097 \\
& H5. Smartphone use $\rightarrow$ Neglect of work & $.457(.384)$ & .092 & 4.945 & $.000^{*}$ \\
\hline \multirow{5}{*}{ Korea } & H1. Ease of use $\rightarrow$ Smartphone use & $.260(.222)$ & .081 & 3.226 & $.001^{*}$ \\
\cline { 2 - 7 } & H2. Emotional lift $\rightarrow$ Smartphone use & $.093(.086)$ & .071 & 1.300 & .194 \\
\cline { 2 - 7 } & H3. POSI $\rightarrow$ Smartphone use & $.032(.030)$ & .069 & .472 & .637 \\
\cline { 2 - 6 } & H4. Flow $\rightarrow$ Smartphone use & $.667(.440)$ & .126 & 5.299 & $.000^{*}$ \\
\cline { 2 - 6 } & H5. Smartphone use $\rightarrow$ Neglect of work & $.619(.476)$ & .084 & 7.361 & $.000^{*}$ \\
\hline
\end{tabular}

Fit: $\mathrm{x}^{2}$ (d.f) $=695.873(318), \mathrm{p}=.000, \mathrm{GFI}=.889, \mathrm{AGFI}=.853, \mathrm{NFI}=.845, \mathrm{CFI}=.908, \mathrm{RMSEA}=.047$

$* \mathrm{p}<0.01$ 
Figure 3. Comparison of U.S. and Korea

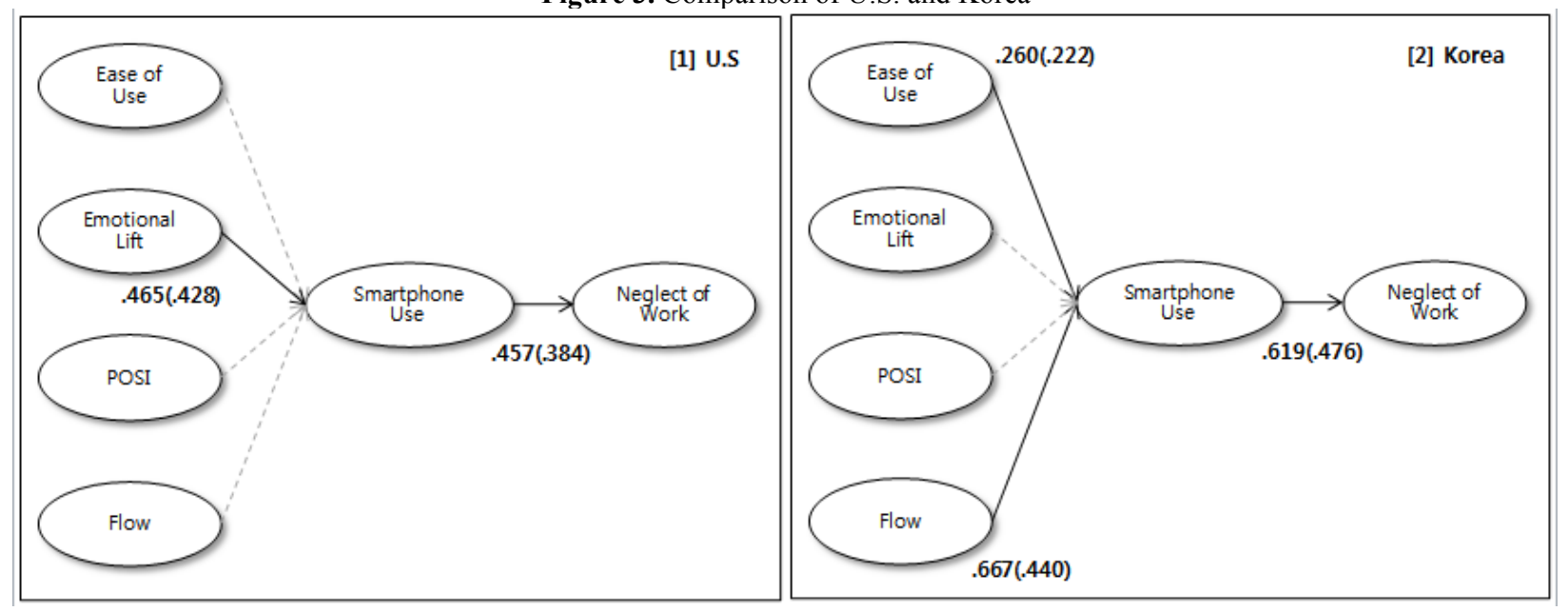

\section{DISCUSSION AND CONCLUSION}

There is a discussion about homogenous user's behaviors toward a new technology because of globalization (Mooij, 2010). Sadik (2008) showed a trend in convergence of technology adoption among industrialized countries. In the study of internet addiction, it is a phenomenon of international prevalence even if there is a difference of addiction rate (Weinstein and Lejoyeux, 2010). Some studies in Korean smartphone addiction show that there is a similar pattern between internet addiction and smartphone addiction (Kwon et al., 2013; Lee, 2013; Seo et al., 2013). Most smartphone addiction studies use a modified internet addiction diagnostic test. They measured severity of smartphone addiction without considering drivers and results. In this study, the authors divided drivers and results of smartphone addiction and compared the outputs of U.S. and Korea. In the previous smartphone addiction study (Caplan, 2010), POSI is a main factor to determine smartphone addiction. In this study, among the four drivers, POSI is not related with smartphone usage behaviors in both countries. According to a paper about SNS network analysis (Jiang et al., 2013), $80 \%$ of online social network users visit a SNS site less than or equal to once a day. In their analysis, $93 \%$ of the online social network users are latent users and most of active interactions are attributed to a very small group of highly interactive users. This implicates that most smartphone users are passive users to read and consume content made by active users like power bloggers. For the passive users of online social networks, POSI is not a strong factor to determine usage behaviors of smartphone.

While flow and ease of use are drivers to influence smartphone addiction in Korea, emotional lift is a driver for U.S. users. In the mobile payment study (Shin, et al., 2014), while Korean users consider convenience as an important factor for their use of mobile payment, U.S. users consider safety as a more important factor. In addition, Korean smartphone users have a higher mobile payment frequency because Korea has developed smartphone payment systems for public transportation. Therefore, Korean smartphone users consider their smartphone as a payment tool. Cho (2009) also argued that while smartphone was a source of entertainment to users in both countries, convenience was the factor more sensitive to Korean mobile users than to U.S. users. Even if convenience is a broader concept of ease of use, ease of use is a very sensitive factor for Korean mobile users. Due to a well deployed wireless network in Korea, Korean smartphone users can access mobile internet even in public transportation. The availability of mobile internet network leads to an increase in the usage frequency and usage hours of smartphone. Because of the prevalence of mobile internet, Korean smartphone users can focus on smartphone activities, which makes flow a significant factor for smartphone use.

Smartphone users have a preference for a specific operating system. The dominant operating systems are Google's Android and Apple's iOS. While Korea is one of the countries with high market share of the Android operating system, Apple is the number one smartphone maker in the U.S. market. In 2012, 90\% of smartphones in Korea had Google's Android operating systems and 9\% of them had Apple's iOS (Shin and Lee, 2014). According to the comScore' report about the U.S. digital future (2014), the U.S. market share of iPhone is $42 \%$ in 2013 . While there is 
only one manufacturer in iOS, many manufacturers exist in Android. The different market shares of the two operating systems in both countries causes different levels of ease to use.

Smartphone use has an influence on neglect of work in both countries. As mentioned in the previous section, there is a serious work-home interference for intense smartphone users because of losing control for smartphone use (Derks and Bakker, 2012). Among academic papers for smartphone addiction, studies with samples of Korean are dominant. Korean Government has a plan to provide a nationwide counseling program for smartphone addiction to its young generations (Nam, 2013). Even if there is a trend of converging user's behaviors because of globalization (Mooij, 2010), drivers for smartphone addiction are different in the U.S. and Korea. However, there is a possibility of prevalence of smartphone addiction in countries with a high smartphone penetration rate.

\section{AUTHOR BIOGRAPHIES}

Seungjae Shin received a Ph.D. in Information Sciences (2003) at the University of Pittsburgh and a Ph.D. in Industrial and Systems Engineering (2013) at Mississippi State University. He is a professor of Information Systems and Supply Chain Management at Mississippi State University, Meridian. His research areas are telecommunications, logistics, and transportation industry analysis.

Won-jun Lee received a Master degree (1996) and a Ph.D. in Marketing (2005) at the Seoul National University. He is currently an associate professor of Business Management at Cheongju University in Korea. His research areas are technology marketing, consumer behavior and e-WOM communication.

\section{REFERENCES}

Bernroider, E., Krumay, B., and Margiol, S. (2014). Not Without My Smartphone! Impacts of Smartphone Addiction on Smartphone Usage, Proceedings of the $25^{\text {th }}$ Australasian Conference on Information Systems, Auckland, New Zealand, December 8 - 10, 2014.

Block, J. (2008). Issues for DSM-V: Internet Addiction, American Journal of Psychiatry, 165 (3): 306-7.

Caplan, S. E. (2010). Theory and Measurement of Generalized Problematic Internet Use: A Two-step Approach, Computers in Human Behavior, 26(5), 1089-1097.

Casey, B. and Leung, L. (2015). Linking Loneliness, Shyness, Smartphone Addiction Symptoms and Patterns of Smartphone Use to Social Capital, Social Science Computer Review, 33 (1), 61-79.

Chen, C. and Mort, G. (2007). Consumers' Technology Adoption Behavior: An Alternative Model, The Marketing Review, 7 (4) 355-368.

Cho, Y. (2008). Assessing user attitudes toward mobile commerce in the U.S. vs. Korea: Implications for m-commerce CRM. The Journal of Business and Economics Research, 6(2), 91-102.

Cho, Y. (2009). A cross-cultural comparison analysis of customer attitudes toward mobile phone services in the U.S. and Korea. International Business \& Economics Research Journal, h, 8(4), 13-25.

Chou, T. and Ting, C. (2003). The Role of Flow Experience in Cyber-Game Addiction, CyberPsychology \& Behavior, 6 (6), 663 675.

comScore. (2014). U.S. Digital Future in Focus, Retrieved from http://www.comscore.com/Insights/Presentations-andWhitepapers/2014/2014-US-Digital-Future-in-Focus

Derks, D. and Bakker, A. (2012). Smartphone Use, Work-Home Interference, and Burnout: A Diary Study on the Role of Recovery, Applied Psychology, 63 (3), 411-440.

Faber, R. and O'Guinn, T. (1992). A Clinical Screener for Compulsive Buying, Journal of Consumer Research, 19(3), 459469.

Hsu, C., Chang, K., and Chen, M. (2012). Flow Experience and Internet Shopping Behavior: Investigating the Moderating Effect of Consumer Characteristics, Systems Research \& Behavioral Science, 29, 317-322.

Huizingh, E. and Hoekstra, J. (2003). Why do consumers Like Websites? Journal of Targeting, Measurement and Analysis for Marketing, 11(4), 350-361.

Jiang, J., Wilson, C., Wang, X., Sha, W., Huang, P., Dai, Y., and Zhao, B. (2013). Understanding Latent Interactions in Online Socail Networks, ACM Transactions on the Web, 7 (18), pp. 1-39.

Kang, S. and Jung, J. (2014). Mobile Communication for Human Needs: A Comparison of Smartphone Use between US and Korea, Computers in Human Behavior, 35, 376-387.

Kim, D., Lee, Y., Lee, J., Nam J. and Chung, Y. (2013). Development of Korea Smartphone Addiction Proneness Scale for Youth, PLoS One, 9(5), pp. 1-8.

Kwon, M., Lee, Y., Won, W., Park, J., Min, J., Hahn, C. Gu, X, Choi, J., and Kim, D. (2013). Development and Validation of a Smartphone Addiction Scale (SAS), PloS One, 8 (2), e56936. 
LaRose, R. (2001). On the Negative Effect of E-Commerce: A Sociocognitive Exploration of Unregulated On-line Buying, Journal of Computer-Mediated Communication, 6 (3), Retrieved from http://onlinelibrary.wiley.com/doi/10.1111/j.1083-6101.2001.tb00120.x/full

Lee, Y. Chang, C., Lin, Y., and Cheng, Z. (2014). The Dark Side of Smartphone Usage: Psychological Traits, Compulsive Behavior and Technostress, Computers in Human Behavior, 31, pp. 373-383.

Lee, U., et al. (2014). Hooked on Smartphone: An Exploratory Study on Smartphone Overuse among College Students in Proceedings of the SIGCHI Conference, Toronto, Ontario, Canada, April 26 - May 1, 2014, pp 2327-2336, http://dl.acm.org/citation.cfm?doid=2556288.2557366

Lee, W. (2013). An Exploratory Study on Addictive Use of Smartphone: Developing SAUS, Journal of Convergence Information Systems, 18(12), 403-407.

Kamssu, A. and Siekpe, L. (2012). Relating Online Flow Experience with Internet Addiction, International Journal of Social Health Information Management, 5 (12), 1-7.

Kibona, L. and Mgaya, G. (2015). Smartphone's Effects on Academic Performance of Higher Learning Students, Journal of Multidisciplinary Engineering Science and Technology, 2 (4), 777-784.

Mok, J., et al., (2014). Latent Class Analysis on Internet and Smartphone Addiction in College Students, Neuropsychiatric Disease and Treatment, 20 May 2014, 817-827.

Mooij, M. (2010). Consumer Behavior across Culture: Consequences for Global Marketing and Advertising $2^{\text {nd }}$ e., Sage Publication, London: UK.

Moore, M. (2009). Compulsive Buying Disorder: Is It Real or Can It Be Measured? Ph.D. Dissertation, Retrieved from https://cdr.lib.unc.edu/indexablecontent/uuid:058d3643-3505-4dd7-90b8-966151fff50a

Nam, I. (2013). A Rising Addiction Among Youth: Smartphone, Wall Street Journal, Retrieved from http://www.wsj.com/articles/SB10001424127887324263404578615162292157222

Nunnally, J. (1967). Psychometric Theory, New York: McGraw-Hill.

Park, B. and Lee, K. (2011). The Effect of Users' Characteristics and Experiential Factors on the Compulsive Usage of the Smartphone, in Proceedings of the Second International Conference on Ubiquitous Computing and Multimedia applications, Daejeon, Korea, April 13-15.

Park, N. and Lee, H. (2013). Nature of Youth Smartphone Addiction in Korea: Diverse Dimensions of Smartphone Use and Individual Traits, Journal of Communication Research, 51 (1), 100-132.

Sadik, J. (2008). Technology Adoption, Convergence, and divergence, European Economic Review, 52 (2), 338-355.

Seo, M., et al. (2013). A Comparative Study of Smartphone and Internet Addiction on Adolescent Psychopathology, Journal of Korean Society Biological Theory Psychiatry, Vol. 19, No. 2, pp 154-162.

Shim, J., Shin, S., and Weiss, M. (2006). Digital Multimedia Broadcasting (DMB): Standards, Competition, and Regulation in South Korea, Journal of Information Technology Theory and Application, 8 (2), 69-81.

Shin, L. (2014). A Comparative Study of Mobile Internet Usage between the U.S. and Korea, Journal of European Psychology Students, 5 (3), pp. 46-55.

Shin, S. and Lee, W. (2014). The Effects of Technology Readiness and Technology Acceptance on NFC Mobile Payment Services in Korea, Journal of Applied Business Research, 30 (6), pp. 1615-1625.

Shin, S., Lee, W., and Odom, D. (2014). A Comparative Study of Smartphone User's Perception and Preference toward Mobile Payment Methods in the U.S. and Korea, Journal of Applied Business Research, 30 (5), pp. 1365-1375.

Venkatesh, V. \& Davis, F. (1996). A Model of the Antecedents of Perceived Ease of Use: Development and Test, Decision Science, 27(3), 451-481.

Voiskounsky, A., Mitina, O., and Avetisova, A. (2004). Playing Online Games: Flow Experience, PsychNology Journal, 2 (3), 259-281.

Weinstein, A. and Lejoyeux, M. (2010). Internet Addiction or Excessive Internet Use, The American Journal of Drug and Alcohol Abuse, 36, 277-283.

Yong, K. (1998). Caught in the Net: How to Recognize the Signs of Internet Addiction and a Winning Strategy for Recovery, New York, NY: John Wiley \& Sons.

Yoo, Y., Lyytinen, K., and Yang, H. (2005). The Role of Standards in Innovation and Diffusion of Broadband Mobile Services: The Case of South Korea, The Journal of Strategic Information Systems, 14 (3), 323-353. 